\title{
A Queda das Nações: 0 Destino dos Sistemas Sociais no Novo Ambiente Midiático
}

\section{Lance Strate}

\section{Resumo}

Marshall McLuhan propôs uma visão midiacêntrica do mundo, expressa em seu famoso aforismo "0 meio é a mensagem". Este ponto de vista, e também o trabalho de McLuhan como acadêmico, foram deliberadamente sufocados por muitos anos, até a internet tornar-se um fenômeno popular na década de 1990. As observações de McLuhan a respeito de eletricidade, tecnologia elétrica e mídia eletrônica, que resultaram na mudança no ambiente mediático da galáxia de Gutenberg para a Via Láctea de Marconi, são essenciais para entender as novas mídias que apareceram nas duas últimas décadas. Ao examinar especificamente a relação entre mídias e organização social, a ascensão do nacionalismo e do Estado-nação é rastreada até a revolução da imprensa no início da Europa moderna, ao passo que, por um lado, as tendências contemporâneas ao globalismo e, por outro lado, a novas formas de localismo e tribalismo, estão associadas com as comunicações eletrônicas e com as novas mídias.

\section{Palavras-chave}

McLuhan, mídia, ecologia midiática, ambiente midiático, mídia impressa, mídias eletrônicas, novas mídias, nacionalismo, globalismo

\section{Lance Stratel strate@fordham.edu}

Lance Strate é Professor de Comunicação e Estudos de Mídia e Diretor dos Estudos Profissionais do programa Novas Mídias da Universidade de Fordham, cidade de Nova York. É autor de , and, e coeditor de diversas antologias, inclusive . 0 presente artigo se baseia em um discurso de abertura apresentado no Congresso Internacional , Universidade de Bolonha e Museo Civico Archeologico, Bolonha, 24-26 de março de 2011.
Ao festejar 0 centenário do nascimento do canadense Marshall McLuhan, parece natural começar considerando a carreira do italiano Galileu Galilei. Entendo que a conexão possa não ser visível à primeira vista, mas creio que é possível traçar uma analogia entre os dois. Afinal de contas, Galileu muitas vezes é considerado o descobridor da física moderna, e McLuhan é frequentemente identificado como fundador dos modernos Estudos de Mídia. Entre suas muitas realizações, Galileu é lembrado por ter apresentado os argumentos conclusivos a favor da visão heliocêntrica do mundo. Como vocês sabem, esta foi terrivelmente polêmica à época, porque significou que os seres humanos não ocupam 0 centro do universo, da galáxia nem do sistema solar. Fora as implicações teológicas deste desafio, a visão heliocêntrica representou um enorme golpe para a autoimagem de uma espécie que se imaginava como o coroamento da criação. Então, é correto propor que, tomando o termo geocêntrico, isolando o prefixo que se refere à Terra, geo, e rearrumando as letras, obtém-se ego, indicando que a visão geocêntrica é, de fato, uma visão egocêntrica.

Não é fácil abrir mão da nossa visão egocêntrica do mundo. Mesmo hoje, quando quase todo 
mundo aceita a visão heliocêntrica, ainda falamos de nascer e pôr do sol. Ainda pensamos como se o sol se deslocasse pelo céu. Ainda sentimos a Terra como se fosse fixa e estável, com o resto do universo disposto ao nosso redor. Independentemente do que nossa cabeça sabe, nosso coração continua geocêntrico. Também somos carbocêntricos, ou seja, padecemos de chauvinismo do carbono, crença de que a única forma de vida possível é a que se baseia no carbono. Em contraste com esta visão carbocêntrica, cientistas e escritores de ficção científica especulam em torno da possibilidade da existência de formas de vida que tenham evoluído naturalmente com base em silício, em vez de carbono. Especulam também sobre a possibilidade de que os circuitos integrados baseados em silício associados com a informática possam um dia atingir a complexidade necessária para serem considerados vivos.

\section{É claro que também continuamos a ser} antropocêntricos, considerando a nossa forma de vida como a mais significativa de todas. Mesmo aceitando a teoria da evolução de Charles Darwin, biólogo inglês, costumamos ver-nos como produto final desse processo, e não como um resultado de mutação e recombinação genética aleatórias que demonstrou algum valor em termos de sobrevivência sob condições ambientais específicas e por um período de tempo relativamente breve. $\mathrm{E}$ acho que, por mais progressistas e cosmopolitas que afirmemos ser, não temos como não ser etnocêntricos, pois cada um de nós é produto de uma determinada experiência culturais que, lá no fundo, acreditamos ser verdadeira e apropriada. Em um espectro que vai do geocêntrico ao carbocêntrico, ao antropocêntrico e ao etnocêntrico, chegamos ao egocêntrico, especialmente forte nas culturas que abraçaram o individualismo, como é o caso das culturas ocidentais modernas.

Egocêntricos que somos, dizemos coisas como, se você não gosta do que está passando na TV, mude de canal, ou, ainda melhor, desligue. E é verdade, posso desligar, posso jogar pela janela, posso até optar por não ter um aparelho. Mas não posso optar por viver em um mundo sem televisão. Assim como posso nunca por os pés em um avião, mas não posso optar por viver em um mundo sem aviões que o sobrevoem. Não posso optar por viver em um mundo sem carros nem rodovias. Não posso optar por viver em um mundo sem cidades nem fábricas. Não posso optar por viver em um mundo sem armas de fogo nem nucleares. A informática usa a expressão: garbage in, garbage out (lixo que entra, lixo que sai), abreviada em inglês como GIG0. A ideia é que os resultados obtidos com um software têm relação direta com 0 que ali é colocado. Isto é verdade no caso de programas simples, criados por um único indivíduo. Mas os softwares gigantescos que administram o mundo, que constituem nossos sistemas financeiros, de controle do tráfego aéreo, de mísseis, as telecomunicações, etc., são produto de colaboração em vasta escala, entre muitos 
programadores diferentes que contribuem com fragmentos de código em áreas especializadas. Acabam ficando tão grandes que estão além do que um indivíduo isolado pode compreender ou controlar. É por isto que ninguém tinha total certeza do que aconteceria com nossos sistemas de computadores quando os dois últimos dígitos do ano passassem de 99 para 00 . Ninguém tinha certeza absoluta de como os retalhos de software reunidos nos imensos programas interagiriam com 0 sistema como um todo. Felizmente, não ocorreu nada de desastroso, mas isto não muda o fato de que não tínhamos total controle da situação.

Não temos controle nem sobre as palavras com que falamos, e pensamos, porque falamos e pensamos em línguas que não nos cabe criar, usando palavras e expressões e seguindo regras de gramática e sintaxe que não são nossas.

0 idioma, seja ele qual for - inglês, italiano, hebraico ou japonês -, é um gigantesco software que roda no wetware do cérebro humano e não pode ser totalmente controlado. Assim sendo, a expressão "lixo quer entra, lixo que sai" não se aplica às línguas, assim como tampouco se aplica à informática. Era devido a essa sensação de não controlar totalmente 0 que dizemos que os antigos faziam referência às musas como fontes de inspiração, e aos demônios como os que nos fazem dizer coisas que melhor seria calar.

Nas culturas ocidentais, a liberdade individual é um valor da mais alta ordem, e a sugestão de que algo pode impor limites à nossa liberdade de escolha é alvo de grande resistência, se não hostilidade. Portanto, por meio do que Sigmund Freud chamou de racionalização, costumamos superestimar nossa liberdade de ação como indivíduos, e alimentamos a ilusão de ter controle. Digo isto para apontar com clareza que nenhum dos dois extremos é correto. Não temos controle total, mas tampouco deixamos totalmente de ter controle. Gravitamos naturalmente para os absolutos, quando a verdade está em algum ponto da área cinza intermediária. Não estou sugerindo que devamos eximir os indivíduos de responsabilidade pessoal, mas que só aceitando e reconhecendo nossas limitações podemos entender quais são nossas responsabilidades e agir em consequência. Como disse McLuhan, "não existe inevitabilidade, em absoluto, desde que haja disposição de contemplar o que está acontecendo" (McLuhan \& Fiore, 1967, p. 25). Foi assim que McLuhan nos despertou.

\section{E - apresso-me a acrescentar - a resposta ao} egocentrismo individual não é 0 egocentrismo coletivo. Não há dúvida de que os grupos têm mais força que os indivíduos, e de que os indivíduos são plasmados por grupos, e não pretendo negar a importância dos aspectos políticos, econômicos e culturais nas questões humanas. Mas as sociedades não são livres de restrições e limitações, os grupos não têm liberdade de criar a realidade como bem lhes parece, todo tipo de construção depende dos materiais que se tem à 
disposição e dos métodos disponíveis para se trabalhar com esses materiais. A Alemanha de Karl Marx com certeza entendeu este ponto básico, e assim viemos a entender que há diferenças entre as sociedades nômades, de caçadores-coletores e agrícola, e entre estas e as sociedades industriais, e agora ainda mais em relação às sociedades da informação.

Na perspectiva de McLuhan, contudo, as mídias são as protagonistas das questões humanas. Sob este ponto de vista, são a fala e a nossa capacidade de comunicação simbólica que distinguem nossa espécie de todas as outras que nos tornaram humanos. É a introdução de sistemas de notação, especialmente a escrita, que vai de par com a transição das sociedades tribais para assentamentos e estruturas sociais complexas, para cidades e impérios - é o que nos torna civilizados no sentido tradicional da palavra. É o tipo peculiar de escrita conhecida como alfabética que nos dá primeiro a cultura da antiga Israel com monoteísmo, lei e ética codificadas e narrativa histórica, e depois a cultura da Grécia antiga com filosofia e ciência, teatro e democracia - é o que nos torna ocidentais. É a invenção da imprensa com tipos móveis, atribuída ao alemão Johann Gutenberg, que nos dá a ciência moderna, a democracia moderna, o Iluminismo, o pluralismo religioso, o romance e a literatura moderna, conceitos de autoria e propriedade intelectual, publicidade e divulgação e muito mais — é o que nos torna modernos. Agora, a introdução e proliferação de mídias eletrônicas nos dois últimos séculos encerraram a era moderna e nos deixaram em uma terra nova que não entendemos bem, de forma que só podemos defini-la pelo que deixa para trás: como pós-moderna.

Caso você tenha alguma dúvida, tudo isto pode ser expresso de forma muito mais econômica na famosa frase de McLuhan (1964): o meio é a mensagem. Isto representa o que podemos chamar de visão midiacêntrica. Do ponto de vista midiacêntrico, as mídias impressas são centrais para o mundo moderno, para o que McLuhan batizou de galáxia de Gutenberg. Tudo o mais é distorcido pela força gravitacional desse centro galáctico, o que faz com que alguns objetos sejam atraídos para o centro e outros sejam ejetados para o espaço sideral, ao passo que a maioria consegue relativa estabilidade girando em torno do centro da galáxia. Tudo na galáxia é influenciado pelo centro galáctico - alguns, porém, mais fortemente que outros - e todos os objetos também estão submetidos a muitas outras influências, pois interagem uns com os outros. Galileu teria entendido esta visão midiacêntrica, e certamente teria podido identificar-se com a forte oposição e os ataques que McLuhan sofreu por desafiar a visão egocêntrica predominante em seu próprio tempo.

Ao contrário de Galileu, McLuhan nunca foi forçado a se retratar e nunca ficou em prisão domiciliar, mas foi alvo de um esforço deliberado para eliminar seu trabalho. Eu não chegaria a 
dizer que se tratou de uma conspiração, porque os ataques partiram de diferentes lugares e por diferentes razões, algumas das quais políticas e ideológicas, outras resultado de preconceito religioso, outras ainda de natureza metodológicas, com base em disputa de território acadêmico, ou baseadas em esnobismo intelectual, ou em inveja de sua popularidade e algumas ainda foram meramente pessoais. Mas tudo isso resultou na exclusão do exame e da discussão séria do trabalho de McLuhan do discurso acadêmico por um período que foi dos anos setenta até os noventa. Os acadêmicos que entendiam a importância de McLuhan só conseguiram romper essas barreiras quando a internet se tornou um fenômeno popular, assim realinhando nossas constelações e exigindo uma perspectiva capaz de dar conta do sentido da mudança tecnológica.

Agora que somos capazes de dar a McLuhan a atenção que merece, também precisamos colocar seu trabalho no contexto do campo mais vasto da ecologia midiática, que 0 acadêmico americano Neil Postman (1970) definiu como o estudo das mídias como ambientes (ver Strate, 2006, 2011; Strate \& Wachtel, 2005). McLuhan é uma das figuras mais centrais nesse campo, embora alguns talvez o coloquem um tiquinho fora do centro, mas faz parte de um panteão que inclui intelectuais como Harold Innis (1951), do Canadá, Eric Havelock (1963) nascido na Inglaterra, Jacques Ellul (1964), da França, Walter Benjamin (1968) da Alemanha, e os americanos Lewis Mumford (1934, 1967, 1970), Susanne Langer (1957),
Dorothy Lee (1959), Walter Ong (1967, 1982), Edmund Carpenter (1973), Susan Sontag (1977) e Neil Postman (1985, 1988, 1992), para manter a tradição do número doze.

Mas alguns vão buscar as raízes filosóficas do campo na antiga Grécia e no Fedro de Platão, que discute os efeitos negativos da palavra escrita, e seus alicerces éticos para na antiga Israel e nos Dez Mandamentos de Moisés, que proíbem a criação de qualquer tipo de representação visual.

Por mais que remontemos ao passado, foi por intermédio de McLuhan que o campo da ecologia da mídia emergiu e adquiriu existência reconhecível, de maneira que, em certo sentido, McLuhan foi a causa formal da ecologia midiática (McLuhan \& McLuhan, 2011). Também aqui podemos ver um paralelo com Galileu que, ao defender a visão heliocêntrica, possibilitou a revolução copernicana. Assim, embora tenha sido posterior a Copérnico, astrônomo polonês, Galileu foi a causa que veio depois do efeito. Em sua história da imprensa no início da modernidade européia, inspirada em McLuhan, Elizabeth Eisenstein, historiadora americana, aponta o mesmo em relação ao Renascimento. 0 Renascimento italiano precedeu imediatamente Gutenberg, motivo pelo qual se tornou o conteúdo das novas mídias impressas e por estas foi consagrado e fixado. Além disso, a explosão de conhecimento resultante da imprensa garantiu que 0 Renascimento italiano não se desvanecesse como os revivals anteriores da aprendizagem, mas se tornasse, ao contrário, a base do progresso 
constante das artes e da ciência. A ideia de que os efeitos podem preceder a causa, que inverte nosso entendimento habitual de causa e efeito, é associada à noção aristotélica de causa formal, tema de recente publicação, Media and Formal Cause, dos coautores Marshall e Eric McLuhan (2011).

Quero frisar aqui que a ecologia midiática não constitui um sistema teórico ou filosófico fechado, mas uma abordagem aberta para se entender quem somos como seres humanos, como plasmamos nossos entornos e como nossos entornos nos plasmam. Como toda coisa viva, adaptamo-nos aos nossos ambientes, e nossos ambientes atuam sobre nós por meio de um processo de seleção natural. E, como toda coisa viva, modificamos nossos ambientes: 0 próprio processo de viver altera 0 entorno, pois os organismos ingerem nutrientes, eliminam resíduos e se reproduzem. Toda coisa viva procura modificar seu ambiente de forma a aumentar sua própria sobrevivência. Mas os ambientes são complexos, e as mudanças introduzidas nem sempre geram resultados favoráveis. Não somos senhores de nossos ambientes, existimos em relações ecológicas. Em nosso universo midiacêntrico, temos o poder de deslanchar mudanças que alteram o centro de nossa galáxia; contudo, a maneira como estas mudanças afetarão 0 resto da galáxia, como nos afetarão, sempre será, até certo ponto, imprevisível.
Embora boa parte do antigo ambiente midiático ainda persistisse, McLuhan (1962) escreveu sobre a Galáxia de Gutenberg como coisa do passado. Agora, meio século depois, a obsolescência do antigo ambiente midiático é muito mais óbvia, e constatamos que salta claramente aos olhos uma nova formação que podemos chamar, seguindo a pista de McLuhan, de Via Láctea de Marconi. McLuhan não está mais aqui para proporcionar insights que nos ajudem a entender nosso novo ambiente midiático, mas, em sua época, o autor foi capaz de vislumbrar a mudança que estava ocorrendo, e sua abordagem nos proporciona um excelente ponto de partida para continuar pesquisando. Em termos simples, identificou corretamente 0 fato de que a maioria das características do ambiente midiático em que hoje vivemos está alicerçada em eletricidade, tecnologias elétricas e mídias eletrônicas. Por exemplo: a eletricidade restaura 0 senso do orgânico que falta na tecnologia mecânicoindustrial, já que o sistema nervoso se baseia em impulsos eletroquímicos - daí a observação de McLuhan (1964) de que as mídias eletrônicas são extensões do sistema nervoso. A eletricidade exige que se feche um circuito, e, portanto introduz a não-linearidade em uma sociedade erigida sobre a linearidade do escrever e do imprimir. Os circuitos elétricos também são binários por natureza, com seus dois estados gêmeos, ligado e desligado, e as polaridades positiva e negativa do eletromagnetismo. A eletricidade mais parece um líquido do que um sólido, e é mais energia do que matéria, introduzindo a desmaterialização 
e a eterealização que caracterizam a era da informação. A corrente elétrica movimenta-se à velocidade da luz e, portanto, apresentanos à instantaneidade. 0 circuito elétrico é, no fundamental, um fenômeno de mão dupla e, portanto, potencialmente interativo. A eletricidade movimenta a energia de uma fonte central para locais periféricos e, portanto, é descentralizadora e democratizante. A combinação dessas características cria um senso de conexão e envolvimento que muitos acham difícil ver na tecnologia de radiodifusão dos anos 1960, mas os insights de McLuhan deram perfeitamente conta da natureza participativa das novas mídias que evoluíram a partir da televisão e das telecomunicações de meados do século XX. A ênfase atual nas novas mídias para a criação de experiência de imersão leva 0 conceito de mídia como ambiente a um patamar totalmente novo.

Com este entendimento da natureza elétrica do novo ambiente midiático, eu agora gostaria de tratar do prefácio de McLuhan (1962) para $A$

\section{Galáxia de Gutenberg:}

Pode ser algo vantajoso substituir a palavra "galáxia" pela expressão "ambiente mundial". Toda tecnologia nova tende a criar novo ambiente humano. A invenção da escrita e a utilização do papiro criaram o ambiente social que associamos com os impérios do mundo antigo. 0 estribo $\mathrm{e}$ a roda criaram ambientes singulares de grande importância. 0s ambientes tecnológicos não são meros recipientes passivos de pessoas, e sim processos ativos que remodelam tanto as pessoas como outras tecnologias. Em nossa época, a súbita passagem da tecnologia mecânica da roda para a tecnologia dos circuitos elétricos representa uma das grandes mudanças de todos os tempos históricos. A impressão com tipos móveis criou um novo ambiente bastante inesperado criou o PÚBLICO. A tecnologia manuscrita não tinha a intensidade nem o poder de extensão necessários à criação de públicos em escala nacional. 0 que chamamos de "nações" nos últimos séculos não precedeu, e não poderia ter precedido, 0 advento da tecnologia de Gutenberg, assim como as nações não podem sobreviver ao advento dos circuitos elétricos com seu poder de envolver totalmente todas as pessoas em todas as outras pessoas. (p. ii)

\section{McLuhan reitera este ponto em Entendendo a}

Mídia (1964), afirmando que "o nacionalismo de hoje... tem todas as mídias eletrônicas contra ele. Nos negócios, assim como na política, 0 efeito até da velocidade do avião a jato é tornar bastante impraticáveis os agrupamentos nacionais mais antigos de organização social" (p. 177). Em outras palavras, McLuhan argumenta que o nacionalismo e os Estados-nação modernos não poderiam existir antes da criação de um ambiente midiático tipográfico, e que não podem sobreviver à sua derrocada. Nosso novo ambiente midiático, dominado pelas mídias eletrônicas, favorece diferentes tipos de arranjos culturais, diversas formas de organização social. Seguindo a pista de McLuhan, escolhi o título "A queda das Nações: 0 Destino dos Sistemas Sociais no Novo Ambiente Midiático" e, ao igualar aqui nações a sistemas sociais, também estou seguindo a pista de Niklas Luhmann (1982, 1989, 1995), sociólogo alemão. A abordagem de Luhmann está fundamentada na teoria sistêmica e, portanto, enfoca toda a sociedade como 
sistema, sendo o sistema um todo composto de partes interdependentes. Costumamos pensar as sociedades como feitas de pessoas, de populações; na visão de Luhmann, contudo, os sistemas sociais são compostos de partes ou unidades de comportamento social que são, na verdade, atos de comunicação.

Daí decorre que as mudanças na maneira como nos comunicamos podem mudar a própria natureza de um sistema social, de forma que, por exemplo, quanto mais elevada a quantidade de atos de comunicação, maior a sociedade. Em sistemas sociais nos quais a comunicação se limita ao boca a boca e à tradição oral, as sociedades tendem a permanecer simples e pequenas, como no caso das tribais. Nessas condições, se 0 volume de informação que está sendo comunicado ficar muito grande, o que ocorreria devido ao crescimento da população, a sociedade se divide, separa-se em dois grupos. A introdução de sistemas de notação, e de escrita, proporciona aos sistemas sociais meios para processar maiores quantidades de informação e, assim, crescer sem se dividir. Daí resultaram não só sociedades maiores como também aumento de complexidade, pois maiores volumes de informação podiam ser organizados por meio de um processo de especialização. Por exemplo: 0 antropólogo inglês Jack Goody (1986) detalhou a forma como a introdução da escrita em sociedades orais esteve associada à criação de instituições formais políticas, religiosas, econômicas e jurídicas. Na perspectiva de Luhmann, esse crescimento é uma questão da diferenciação da sociedade, uma espécie de crescimento fractal na complexidade, bem como no tamanho e na importância. Este processo continua ao passarmos da escrita para a imprensa, resultando no Estado-nação moderno.

A abordagem de Luhmann ajuda-nos a pensar a nação como forma de organização social, mas não trata da ideia de nação como forma de unidade cultural. Neste sentido, eu evocaria a afirmação incisiva do antropólogo americano Edward T. Hall (1959), segundo a qual "cultura é comunicação, e comunicação é cultura". E recorreria ao cientista político tcheco Karl Deutsch, que enfatizou a comunicação social como um determinante de unidade nacional, pois, a seu ver, a emergência de uma cultura nacional exige o desenvolvimento de "hábitos complementares e facilidade de comunicação" (p. 70). Segundo Deutsch, fatores tais como geografia, etnicidade, linguagem e religião são funcionalmente equivalentes e podem, em qualquer combinação, gerar "complementaridade suficiente para produzir o resultado geral" (p. 71) de coesão social. Daí decorre que as culturas orais não sejam capazes de manter a complementaridade além de uma população limitada, seja esta uma tribo nômade ou uma comunidade assentada em aldeia. No mundo antigo, a escrita permitiu a formação de unidades culturais maiores, tais como as cidades-estado, e, às vezes, emergia um senso mais amplo de coesão social. Na antiga Israel, por exemplo, após o surgimento do primeiro alfabeto, 
conseguiu-se certo grau de complementaridade por meio do compartilhamento de sistema escrito, literatura sagrada e religião. Mas, longe de ser estável, a unidade das doze tribos só foi conseguida brevemente, sob o reinado dos reis Davi e Salomão, para depois tornar a fragmentar-se. No mesmo sentido, surgiu, entre as cidades-estado da antiga Grécia, uma tendência conhecida como pan-helenismo após a adoção do alfabeto, que possibilitou a difusão de uma literatura comum sob forma dos épicos de Homero, da síntese de uma religião comum por meio de instituições tais como 0 Oráculo de Delfos, e por intermédio da criação dos Jogos Olímpicos (Nagy, 1979). Mas não se conseguiu união política e uma aliança militar muito laxa só foi formada diante de ameaças comuns, como a do Império Persa.

A exemplo de outras cidades imperiais, Roma, em contraste, instituiu uma forma de unidade política e econômica mediante força militar, utilizando a comunicação para fins de comando e controle. Como Harold Innis (1951) apontou claramente, os sistemas de escrita, conjugados com superfícies leves para escrever, tais como papiro e papel, proporcionaram a necessária extensão da capacidade de comunicação para enviar e receber mensagens à distância com fidelidade e eficiência. A administração dos territórios também foi facilitada pela capacidade de manter registros escritos de leis e éditos, contratos e tratados, contas e inventários, de criar crônicas e histórias e de realizar censos. Os impérios da antiguidade destacaram-se no exercício do controle militar, político e econômico, mas as tentativas de impor o idioma, a religião e os costumes da comunidade governante tiveram sucesso muito limitado, e apenas entre as elites dos territórios subjugados. 0 imperialismo cultural foi quase impossível de alcançar, e geralmente não valeu o esforço. Em outras palavras, a escrita proporcionou complementaridade de comunicação suficiente para conseguir unidade ou política ou cultural, mas não ambas. No ambiente midiático dos escribas, na antiguidade e idade média, encontramos uma variada mescla de diferentes tipos de sistemas sociais, de tribos e aldeias a cidades-estado e alianças culturais laxas, de dominação imperial à estrutura descentralizada de poder do feudalismo. Encontramos também redes religiosas que transcendem tanto as comunidades locais como os impérios, exibindo elementos de unidade política e cultural, mas permanecendo consideravelmente aquém do nacionalismo.

Assim, retornamos à palavra impressa como "arquiteta do nacionalismo" (p. 170), como diz McLuhan (1964). Até certo ponto, construir uma nação não é totalmente diferente de construir um império, pois ambas implicam governar um território à distância a partir da capital, cidade central. Neste sentido, a extensão dos vieses da palavra escrita por meio da tipografia ajudou a expansão territorial na forma tanto de impérios como de nações e, é claro, ambos às vezes ocorrem simultaneamente. A imprensa facilitou 
as comunicações de comando e controle, mas, com capacidade sem precedentes de comunicar de um para muitos, as mídias impressas podiam ser usadas para conseguir um grau também sem precedentes de uniformidade política, por exemplo mediante a ampla distribuição de exemplares idênticos de leis e constituições. Os procedimentos governamentais, jurídicos e militares foram homogeneizados através da produção de manuais e formulários (Eisenstein, 1979). De fato, é fácil deixar de considerar o formulário em branco como uma inovação introduzida pela revolução da imprensa, e também como mídia impressa. 0 formulário em branco está tão em branco quanto um barril de gasolina que é esvaziado de gasolina está realmente vazio, problema de linguagem identificado por Benjamin Lee Whorf (1956), linguista e inspetor de seguros americano. 0 formulário impresso é 0 alicerce da organização burocrática. E a organização burocrática é uma tecnologia de controle e um exemplo chave do princípio de diferenciação que Luhmann (1982, 1995) examina. Além disto, os sistemas econômicos foram ainda mais integrados por meio da impressão de papel-moeda e outros documentos financeiros (Eisenstein, 1979; McLuhan, 1964).

A coerção e o controle puderam ser suplementados pela produção de propaganda política impressa. 0 aumento das taxas de alfabetização, propiciado pela disponibilidade de mídias impressas, e a criação de escolas significaram que parcelas maiores de uma população seriam suscetíveis à persuasão $\mathrm{e}$ à propaganda tipográficas (Ellul, 1965). E toda a população podia ser influenciada pela distribuição de símbolos nacionalista sob forma de imagens impressas, tais como fotos de monarcas, estadistas, líderes militares e outros heróis nacionais (Braudy, 1986; Eisenstein, 1979). Não admira que, com a proliferação dos impressos, as autoridades centrais tenham tentado colocar essa atividade sob seu controle. Mesmo quando o controle e a censura enfraqueciam, a propaganda antigovernamental era acompanhada por, no pior dos casos, uma revolução nacional, não pela desintegração nacional (ver, por exemplo, Coward, 1980).

As mídias impressas também ajudaram a deslizar sutilmente a lealdade da localidade para a nação. Por sua própria natureza, a cultura oral é conservadora e comunitária. A escrita permite que os indivíduos tomem distância de suas tradições e as avaliem criticamente (Havelock, 1963; Ong, 1967, 1982), o que abre as portas para 0 individualismo, na medida em que ler e escrever são atividades isoladas, privadas (McLuhan, 1962; Ong, 1967, 1982).

A separação em relação à tribo e à comunidade local permite que os indivíduos sintam uma conexão com uma "comunidade imaginada" maior, mais abstrata, para usar a expressão que 0 cientista político americano Benedict Anderson (1983) tornou famosa. Os indivíduos libertos da 
tradição e do tribalismo formam o que chamei de público, residindo na esfera pública alfabetizada e urbana longamente discutida pelo sociólogo alemão Jürgen Habermas (1989).

Mas esses indivíduos isolados acabam tornandose parte de uma massa, membros de uma sociedade de massas (Ellul, 1965).

Antes da difusão da tecnologia da impressão, as comunidades locais podiam existir em relativo isolamento; era pouco frequente, $\mathrm{e}$ consideravelmente defasada, a chegada de notícias do mundo externo.

As mídias impressas tornaram possível a distribuição de notícias com maior regularidade e velocidade, levando assim a atenção do local para 0 nacional. Quando difundidas oralmente, as notícias eram mediadas pelas elites locais, tais como um padre ou pastor; as mídias impressas contornavam as elites locais e entregavam a informação diretamente aos indivíduos (Eisenstein, 1979). A ampliação do acesso à informação sobre as questões nacionais levou a um maior desejo de participar na tomada de decisões políticas, particularmente por parte daquela que foi responsável, em grande medida, pela elevação das taxas de alfabetização: a classe média. Desta maneira, o nacionalismo estava estreitamente relacionado com as revoluções democráticas, e democratização e centralização de governo andavam de par com a unidade nacional e a criação de uma cultura política uniforme (Steinberg, 1974).
0 desenvolvimento de ciência e tecnologia, incitado pela revolução da imprensa (Eisenstein, 1979), possibilitou a determinação de fronteiras precisas entre nações, ao passo que o maior controle político e militar facilitou o policiamento dessas fronteiras (Knelman, 1978). 0s mapas impressos deram expressão visual à ideia de que sua própria nação era separada das outras e, ao mesmo tempo, serviam de símbolo de unidade interna dentro dos limites nacionais. A imprensa teve relação com a fixação de fronteiras tanto linguísticas como geográficas. A importância do latim como língua internacional recuou em favor do vernáculo (Chaytor, 1945; Eisenstein, 1979; Innis, 1951; McLuhan, 1962, 1964; Steinberg, 1974). Como diz o historiador inglês da imprensa, S. H. Steinberg, "a prensa... preservou e codificou, às vezes até criou, o vernáculo; no caso de povos numericamente pequenos e economicamente fracos, é possível demonstrar que sua ausência levou ao desaparecimento destes ou, pelo menos, a sua exclusão do campo da literatura" (p. 120). Por falta de uma prensa, dialetos como os da Cornualha e da Prússia nunca se tornaram idiomas cabais, ao passo que as mídias impressas permitiram que os holandeses diferenciassem sua língua do alemão, e possibilitaram a preservação e a codificação de idiomas tais como 0 galês, 0 gaélico, 0 catalão e o basco. A imprensa "fortaleceu as 'muralhas da língua' entre as nações" (Steinberg, 1974, p. 123) e também homogeneizou o idioma dentro de cada nação. Geralmente localizadas no centro político e econômico da nação, as gráficas instituíram 0 
dialeto do centro como língua literária da nação e usaram seus poderes editoriais para eliminar outros dialetos dos textos que publicavam. A publicação de livros de gramática e da criação de escolas de gramática minimizou as variações regionais da fala e da escrita. Mesmo em países com mais de uma língua nacional, a homogeneização dos idiomas oficiais contribui para a criação de unidade cultural dentro das nações, e para separá-las umas das outras.

Em muitos casos, o primeiro texto impresso em vernáculo foi a Bíblia, o que favoreceu a sensação de que Deus falava naturalmente na língua da nação e, na verdade, era cidadão do país. A imprensa solapou o poder da Igreja como sistema social, assim rivalizando com o Estado. Além disso, a tarefa de reproduzir outros textos e documentos religiosos, tais como livros de oração, foi transferida dos escribas, controlados pela Igreja, para os gráficos, controlados pelo Estado (Eisenstein, 1979). A imprensa foi associada à Reforma Protestante, que em parte se baseou no fato de que as pessoas agora tinham fácil acesso à Bíblia e não precisavam da mediação de padres (Innis, 1951); os protestantes também fizeram generoso uso da imprensa para fins de propaganda (Eisenstein, 1979). 0 resultado disto, pelo menos de início, foi a formação de religiões nacionais em países que rejeitavam a Igreja de Roma, reforçando ainda mais o nacionalismo. A identidade nacional dos países que permaneceram católicos ainda era fortalecida por meio do contraste com as nações vizinhas que se tornaram protestantes. Nos países em que a homogeneidade religiosa foi substituída por seitas e crenças concorrentes, o pluralismo e a necessidade de tolerância enfraqueceram ainda mais a Igreja em relação ao Estado, deixando o patriotismo como única religião nacional restante.

A impressão de Bíblias em vernáculo muitas vezes foi o primeiro passo para o estabelecimento de uma língua literária nacional e a criação de um corpo de literatura nacional (Eisenstein, 1979). 0 desenvolvimento do romance coincidiu com a ascensão do nacionalismo, algo que muitos teóricos da cultura enfatizam, inclusive Benedict Anderson (1983). Mas as obras históricas e biográficas também ajudaram a construir um passado comum e um senso de cultura compartilhada. Os escritores, filósofos, cientistas, etc., do país eram celebrados como heróis nacionais e sua obra constituía um cânon nacional (Steinberg, 1974). Até certo ponto, foram criadas tradições intelectuais independentes, tais como 0 racionalismo francês e 0 empirismo britânico. Assim, por meio da publicação de literatura nacional, a imprensa facilitou a coesão cultural, unidade que foi reforçada por meio da instrução escolar "livresca".

A imprensa abriu as portas ao nacionalismo ao criar comunicação complementar suficiente para permitir que os agrupamentos locais se juntassem em um sistema social maior. Em algum momento, os grupos locais opuseram, 
naturalmente, resistência a este esforço, de forma que o nacionalismo entrou em conflito com o localismo e foi necessário solapar e romper os laços e lealdades locais para conseguir uma coesão cultural mais ampla. Em outras palavras: o sistema social mais amplo tinha de absorver, digerir e metabolizar os menores no intuito de criar uma cultura nacional homogênea, o que foi possível graças às tendências homogeneizantes da tipografia (Eisenstein, 1979; McLuhan, 1962, 1964; Steinberg, 1974). Como sistema social complexo, a nação desenvolve numerosos subsistemas especializados dedicados a política, justiça, finanças, religião, educação, defesa e guerra, etc. (Luhmann, 1982, 1989, 1995). Todos esses subsistemas são organizados pelas tendências homogeneizantes da imprensa, e submetidos a esta; e, como partes interdependentes que compõem um todo, são reunidos e coordenados pelas comunicações tipográficas. A imprensa está no centro desta galáxia, mas sua atração gravitacional afeta de forma diferente as diversas partes da galáxia, algumas em movimento mais rápido, algumas mais lentas, algumas gradualmente, algumas com súbita violência. Outros objetos na galáxia também exercem alguma influência, inclusive geografia e história, tecnologias de transporte e novas invenções como a máquina a vapor, a fotografia e o telégrafo (Carey, 1989, 1997; Czitrom, 1983; Innis, 1951; Sontag, 1977). 0 industrialismo estendeu a centralização de poder e as tendências homogeneizantes da imprensa, a fotografia realçou a produção de símbolos de unidade cultural e a telegrafia serviu para estreitar ainda mais os laços de unidade política, econômica e cultural das nações.

James W. Carey (1989), acadêmico americano da área da comunicação, argumentou que a invenção do telégrafo foi peça fundamental na criação de condições para os movimentos de unidade nacional do século XIX na Itália, na Alemanha e em outras partes da Europa. Estes também se estenderam aos Estados Unidos, onde a Guerra Civil pôs termo à ideia de que os estados eram verdadeiras entidades soberanas. Chamamos isso de unidade nacional, mas também pode ser considerado como movimento rumo a algo mais do que uma nação. Ao ver-nos a nós mesmos como nação, nós, nos EUA, também encaramos a União das Repúblicas Socialistas Soviéticas como uma nação, como uma Rússia maior, não como a união internacional que a própria URSS afirmava ser. Mas o mesmo ambiente midiático que suscitou a União Soviética também testemunhou a amplificação do nacionalismo associada com a ascensão do fascismo e do Nazismo. 0 nacionalismo do século XIX contradisse a previsão marxista de que 0 Estado definharia (Marx \& Engels, 1965), e 0 ultranacionalismo do início do século XX incitou o italiano Antonio Gramsci (1972) a encontrar um modo de incorporar 0 conceito de cultura à teoria marxiana. Se, contudo, deixarmos de lado as ideologias, veremos o fio comum que une 0 nacionalismo dos últimos 150 anos ao comunismo do século XX, à criação da Liga das Nações e 
das Nações Unidas, bem como de outros tipos de instituições internacionais, inclusive a União Europeia. Em termos simples, a revolução na tecnologia da comunicação, que começou no século XIX, serviu de suporte para a criação de unidades políticas e culturais cada vez maiores.

Quer um dado sistema social seja visto como nação única, federação de Estados ou união internacional, sob um ponto de vista é natural que procure uma progressão natural do nacionalismo para o globalismo. Nossa capacidade de comunicação à distância ampliou-se via radiodifusão, telecomunicações, transmissões por satélite e internet, de forma que, sob muitos ângulos, somos um só mundo unido por comunicações instantâneas - 0 que, por sua vez, facilita a administração em escala planetária. Estamos longe de alcançar uma unidade política mundial, mas temos uma economia global e um número limitado de instituições militares, políticas e jurídicas internacionais, e enfrentamos uma lista crescente de preocupações globais, como economia, meio ambiente, proliferação nuclear, terrorismo e direitos humanos. Para lidar com esses problemas, os sistemas sociais menores precisarão unir-se para formar unidades maiores, e um sistema social maior terá de desenvolver subsistemas em escalas internacional e mundial. 0 bom é que nosso novo ambiente midiático gera informação suficiente para possibilitá-lo. Gera também comunicação complementar suficiente para servir de suporte à cultura global emergente. Isto inclui 0 advento de idiomas mundiais, como o inglês e o mandarim, e de literatura mundial, cinema e televisão globais e música mundial (world music). Inclui também as imagens do planeta Terra tomadas do espaço que, como apontou McLuhan, mostram um mundo sem fronteiras.

Acredito podermos dizer que, nas democracias liberais ocidentais, muitos acham a ideia de unidade global atraente, de maneira que alguma forma de cosmopolitismo é compartilhada por comunistas e capitalistas multinacionais, para não mencionar as elites intelectuais. Acrescente-se que visões positivas, quando não utópicas, de um futuro no qual haverá um governo mundial unificado são bastante comuns na cultura popular. Também temos imagens menos específicas de uma futura "irmandade humana", quando "o mundo viverá como um só", para usar frases de "Imagine", de John Lennon, que é, essencialmente, 0 Manifesto comunista em forma de canção. McLuhan era bastante conservador e não simpatizava com Marx, mas suas próprias opiniões não eram tão diferentes das do autor alemão na Galáxia de Gutenberg (1962), onde escreve que "a nova interdependência eletrônica recria o mundo à imagem de uma aldeia global" (p. 31; ver também McLuhan \& Powers, 1989). Na superfície, a expressão "aldeia global" parece uma forma poética de referir-se às comunicações internacionais, interculturais e globais, bem como à globalização de maneira geral. De certo modo, tornou-se intercambiável com a expressão 
evocativa do futurista americano Buckminster Fuller (1971) - "nave Terra" - para referir-se a um novo tipo de perspectiva, que poderíamos chamar de ecocêntrica, pois é baseada em uma visão ecológica do mundo. Além de poética, a expressão aldeia global também pode ser vista como profética, já que antecipa a internet e a World-Wide Web, e nosso novo ambiente das mídias sociais - com Twitter feeds, atualizações de status do Facebook e vídeos do YouTube -, juntamente com as numerosas inovações em telecomunicações com e sem fio e por satélite que surgiram ao longo dos anos.

Não há dúvida de que o globalismo é uma característica de nossa Via Láctea de Marconi. Mas a ideia popular de progresso constante em direção a um governo mundial, e de sistemas sociais que se fundiriam alegremente em um sistema mundial único é inadequada. As nações não entrarão com brandura nessa boa noite. Como apontou McLuhan, o mundo ocidental está fortemente comprometido com as instituições e arranjos desenvolvidos a partir do antigo ambiente midiático, dos quais não abrirá mão facilmente - daí a observação de Gramsci (1972) relativa à hegemonia cultural. Da Galáxia de Gutenberg emergiram não apenas o nacionalismo e 0 Estado-nação moderno, mas sim, como 0 brilhante cientista político canadense Ronald Deibert (1997) examinou detalhadamente, um sistema internacional alicerçado em relações entre nações soberanas. As nações têm interesses adquiridos no sistema internacional, assim como na existência de outros Estados-nação, não só para fins de comércio e aliança, mas simplesmente para reforçar a legitimidade de seus próprios sistemas sociais. Assim, no transcurso da primeira metade do século XX, o Estado-nação emergiu como única forma legítima de organização social. Os impérios coloniais foram desmantelados, os Estadosnação existentes tentaram, com resultados variáveis, transformar ex-colônias em nações à sua própria imagem. As Nações Unidas são ostensivamente um governo mundial, mas foram de grande importância na promoção do sistema internacional de Estados-nação, e podese esperar que venham a ser uma instituição conservadora, se não regressiva, diante de futuros esforços em criar uma verdadeira unidade global. Nesta perspectiva, nacionalismo e globalismo estão, em última instância, em conflito um com o outro, e só será possível realizar a verdadeira unidade global mediante renúncia à soberania do Estado-nação, o fim das lealdades nacionais e da fidelidade patriótica e o declínio das nações. Não será um processo fácil; haverá luta, conflito, violência e guerra. No final, contudo, as nações declinarão porque o novo ambiente midiático não tem como dar-lhes suporte.

Pode parecer que acabo de traçar dois cenários concorrentes e contraditórios, um de transição pacífica, outro de revolução violenta, mas ambas as possibilidades podem coexistir, e de fato coexistem, em meio às complexas interrelações que formam a Via Láctea de Marconi. Deixando 
de lado as inadequações da teorização de Marx do início do século XIX, podemos enxergar em sua visão do futuro tanto um movimento de avanço em direção a um mundo unificado quanto um de retrocesso para o localismo da comuna. A expressão "aldeia global" também tem algo de oximoro, perdido em seus usos mais populares, pois a aldeia é a menor unidade de assentamento humano, ao passo que o globo é a maior. Assim como Marx, McLuhan indica um retorno ao localismo, mas um novo tipo de localismo em escala mundial. Em Entendendo a mídia, McLuhan (1964) escreve que "eletricamente contraído, o globo já não é mais do que uma aldeia" (p. 5) e escreve também que "a família humana volta a ser uma tribo" (p. 172). 0 retorno a um novo tipo de tribalismo é uma tema ubíquo em Entendendo a mídia, e é claro que a aldeia e a tribo, dois sistemas sociais não exatamente equivalentes, são metáforas usadas para tentar compreender 0 sentido de fenômenos que mal começavam a se desenrolar.

A capacidade das mídias eletrônicas de propiciar comunicações instantâneas à distância dá suporte ao globalismo, mas suas tendências descentralizantes favorecem um renovado localismo, duas características que podem parecer contraditórias, mas isto é coerente com a nãolinearidade da tecnologia elétrica. São, além disto, unidas por um inimigo comum, por assim dizer, já que ambas trabalham contra a nação, atacando-a por cima e por baixo. Em relação ao localismo, as últimas várias décadas distinguiram- se por uma crescente tendência ao separatismo e à ressurgência étnica. 0 termo "nacionalismo" foi aplicado a esses movimentos, mas não se trata do nacionalismo da Galáxia de Gutenberg, não são impulsos no sentido de realizar a unidade nacional nem esforços em construir a nação; estamos diante de ruptura, ou de decomposição de Estados e uniões, não de uma síntese culturais, mas de uma cismogênese. 0 exemplo mais dramático disto foi o a separação da União Soviética; o exemplo mais violento, pelo menos na Europa, foi o desmembramento da Iugoslávia; e também testemunhamos a partição de Chipre e a divisão pacífica da Tchecoslováquia. Alguns dos movimentos separatistas mais conhecidos da Europa são os de flamengos e valões na Bélgica, de bascos e catalães na Espanha, de galeses e escoceses na Grã-Bretanha, de bretões, corsos e também bascos na França, e a Liga Norte na Itália.

Na América do Norte, pode-se dizer que 0 Canadá é um Estado fracassado, sendo o dos quebequenses o movimento secessionista com mais visibilidade, enquanto o México teve de lutar com os Zapatistas em seu estado de Chiapas.

Os Estados Unidos, como muitos outros países do hemisfério ocidental, precisaram enfrentar dificuldades relacionadas com a autonomia de seus povos indígenas, e tivemos nossos próprios problemas quanto à independência de Porto Rico, preocupações com populações hispânicas e nacionalismo negro, bem como com movimentos separatistas remanescentes em estados que haviam sido independentes, tais 
como Vermont, Texas, Havaí, e a confederação do Sul. Existe até uma intrigante proposta de que os estados americanos do Noroeste da costa do Pacífico unam-se à província canadense de Colúmbia Britânica e formem a República da Cascádia. Muito mais sérios são os movimentos independentistas fora do mundo ocidental, notadamente entre os tibetanos e mongóis em relação à China, e os palestinos e curdos no Oriente Médio. A ocupação americana do Iraque abriu 0 questionamento de se deveria ser permitido àquele Estado dividir-se em três menores, e os Estados Unidos, como produto de nacionalismo baseado na imprensa, naturalmente favoreceram a opção de construção nacional, e não de ruptura da nação.

As democracias liberais ocidentais apoiam o direito de cada povo à autodeterminação, princípio incluído na Carta das Nações Unidas. 0 problema, é claro, é que não existe definição do que constitui um povo. Parece bem claro quando se trata da fragmentação de um império, do 0 apoio a ser dado aos direitos das populações e colônias conquistadas à autonomia e à liberdade. No entanto, dentro de qualquer grupo que obtém soberania independente, emerge uma minoria que busca sua própria autonomia, e, caso organize um movimento separatista bem sucedido, este subgrupo acabará enfrentando um subgrupo dentro de si mesmo que busca seu próprio status independente. A autodeterminação é interminavelmente complicada por lógica fractal. Além disso, como argumentou o teórico americano da mídia Joshua Meyrowitz (1985), em um ambiente midiático eletrônico, no qual todos estão a par dos assuntos de todos os outros, cada grupo quer o que os outros grupos têm, todos querem igual direito de ser diferente, afirmar a identidade de seu próprio grupo independente, 0 que leva naturalmente ao seu direito à soberania. Ao invés da construção de nações, assistimos à demolição de nações. De fato, como as nações são naturalmente resistentes ao globalismo, a ruptura de nações é uma etapa natural rumo à criação de uma unidade global. Os Estados-nação foram construídos para sobreviver sozinhos, ficar de pé por si sós, mas, ao se fragmentarem, as partes serão menos capazes de manter-se sozinhas e mais dependentes da integração a um sistema social global. Desta maneira, como indicou Marx, globalismo e comunitarismo não são incompatíveis um com o outro.

Considerações políticas à parte, nos Estados Unidos e em outros lugares também assistimos à emergência de economias locais, inclusive unidade monetárias locais que são uma forma modificada de sistema de escambo. Esses fenômenos, encarados com desaprovação pelo governo federal, sinalizam um retorno à comuna e à aldeia, mas o localismo financeiro e 0 uso de moeda não-governamental conheceram rápido ascenso nos últimos anos no mundo todo ao amparo da informática e da transmissão eletrônica de dados (Rushkoff, 2009); no setor econômico, assim como na esfera política, o localismo pode funcionar de 
par com o globalismo, pois as moedas locais e global, juntas, desafiam o reino dos sistemas monetários nacionais. Além disso, a internet também deu apoio ao comércio local através de sites em que indivíduos podem postar recomendações e avaliações de negócios, como Yelp, ou obter cupons e descontos, como Groupon, ou comprar e vender produtos, como Craigslist, ou postar e procurar anúncios de emprego, como Monster.com.

A recente tendência de geolocalização nas mídias sociais, à qual Foursquare deu destaque e a seguir foi incorporada ao Twitter e ao Facebook, também dá nova ênfase ao local, a exemplo da adição de elementos de game em atividades como geocaching e caças ao scavenger pelo celular. 0 desenvolvimento de tecnologia de realidade aumentada e computação ubiqua, e mesmo o uso de códigos QR impressos que podem ser lidos por dispositivos móveis, estão proporcionando uma cobertura (overlay) eletrônica a localidades, assim como, no passado, sinais e números transformavam as localidades em textos que podiam ser lidos e processados de maneira tipográfica. As mídias eletrônicas também ajudaram a romper o monopólio do Estado sobre a força militar, ajudando a organização de milícias locais e agrupações terroristas; como aponta Peter Drucker (1989), acadêmico da área de administração de empresas nascido na Áustria, "o terrorista reinstaurou o exército privado" (p. 54), instituição que fora eliminada no Ocidente pelos governos nacionais durante o século XVII. As comunicações mediadas pela eletrônica podem, com a mesma facilidade, ser usadas para fazer propaganda de movimentos separatistas e servir às comunidades por meio da promoção de negócios locais, de política, de serviços públicos ou de eventos religiosos. Sem dúvida, o revival de dialetos e idiomas minoritários que as mídias eletrônicas, a começar pelo rádio, possibilitaram, serviu de suporte à fragmentação das culturas nacionais, assim como a impressão em vernáculo ajudou a construí-las.

McLuhan (1964) observou que as mídias eletrônicas eliminam as distinções centroperiferia, de forma que qualquer local poderia servir de centro de comunicação. E as mídias eletrônicas superam a distância física, conectando indivíduos em comunicação instantânea. As mídias impressas podem facilmente ser confiscadas nas fronteiras, mas as ondas eletromagnéticas não conhecem limites. 0 maior acesso à radiodifusão e às transmissões por satélite com certeza foi importante na desintegração da União Soviética e em outras revoluções democráticas do final do século XX; agora estamos vendo que os mecanismos de busca, as mídias sociais e a comunicação móvel podem facilitar as rebeliões políticas no século XXI. Nossas novas mídias não detêm uma bala, mas podem ajudar as pessoas a se organizarem, e podem fazer com que seja difícil ocultar de seu próprio povo, bem como de um público global, as atividades governamentais e militares. Também podem fornecer ao governo informações 
sobre os oposicionistas, pois maior acesso e transparência funcionam para ambos os lados. Contudo, o potencial de perturbação é bastante claro, e podemos esperar que continuem as ondas de protesto e revolução, como a que vimos recentemente no Oriente Médio, desencadeada por uma canção rap tunisiana postada no Facebook.

Agora também podemos ver que imigrantes e comunidades de diáspora não sentem mais a mesma pressão para se assimilarem que há meio século, pois hoje podem continuar sendo cidadãos virtuais de seu país de origem. Neste sentido, as identidades nacionais e étnicas estão menos confinadas à localização física do que nunca antes, e tornam-se mais uma questão de conexão via meios de comunicação. A existência de populações não assimiladas constitui outro golpe para a nação e representa a emergência de novas formas de sistemas sociais que podem ser globais no alcance, mas locais ou nacionais no tamanho e escopo.

Isto se aplica aos negócios, pois os negócios locais agora têm uma base mundial de clientes, ao passo que as corporações multinacionais ofuscam muitas das nações do mundo, funcionando como entidades soberanas de facto; é só uma questão de tempo para que exijam ser equiparadas às nações do mundo. A mesma tendência se aplica à religião organizada, há muito transcende limites nacionais. As lealdades que um dia se deslocaram da Igreja para o Estado agora estão percorrendo o caminho inverso, pois as novas mídias permitem que as religiões estreitem cada vez mais os laços entre seus seguidores; isto é verdade tanto para religiões mundiais, como o catolicismo e 0 islamismo, quanto para pequenos cultos, que podem arregimentar um número significativo de seguidores que de outra maneira ficariam espalhados por uma diversidade de lugares. A mesma tendência se aplica a organizações criminosas como o Cartel de Medellín, na Colômbia, e as tríades chinesas em Hong Kong, e a grupos terroristas que, como $\mathrm{Al}$ Qaeda, estão dispersos por numerosos estados diferentes. Em um mundo não-linear, em rede, não existem fronteiras nem linhas de batalha; terrorismo é guerra descentralizada.

\section{O termo glocalização aponta para a nova} realidade em que o local pode operar em escala global, embora a escala às vezes seja algo menos do que global, e o local às vezes seja algo mais parecido ao nacional. Mais importante do que as especificidades é 0 fato de que as antigas noções tanto de topografia como de tipografia não mais se aplicam. McLuhan $(1962,1964)$ apontou 0 alfabeto e a imprensa como forças homogeneizantes, que acentuam a uniformidade e a repetibilidade e geram 0 espaço homogêneo de Aristóteles, Euclides e Newton. A tecnologia elétrica e as mídias eletrônicas desfazem os efeitos homogeneizantes da imprensa, originando o espaço relativista de Einstein. Assim, encontramo-nos em uma paisagem cada vez mais heterogênea que consiste em sistemas sociais múltiplos e superpostos, alguns deles locais, outros nacionais e outros ainda globais. Em vez de apenas uma unidade cultural e política, temos 
numerosas filiações diferentes, algumas das quais são estruturas formais - como as empresas, as religiões organizadas e as burocracias governamentais -, algumas são divisões menos formais baseadas em idioma, cultura, demografia e psicografia, e outras se baseiam em afinidades e interesses comuns por atividades artísticas, de entretenimento e de lazer. Somos, ao mesmo tempo, cidadãos do mundo e cidadãos de uma série de diferentes sistemas políticos, culturais e sociais. No ambiente midiático oral, a identidade centrava-se no grupo e não era possível não pertencer à tribo. No ambiente mediático impresso, a identidade individual passou a ser a norma, exigindo que o indivíduo jurasse lealdade à nação. No novo ambiente midiático eletrônico, o indivíduo torna-se uma multiplicidade de selfs, capaz de lealdades diversas, superpostas e até contraditórias. Estamos entrando em um tempo de complexidade sem precedentes na história humana, porque não se trata apenas de crescimento, de um sistema social maior com mais subsistemas especializados, e sim da passagem dos organismos unicelulares à vida multicelular. Para entendermos a futura estrutura dos sistemas sociais, precisamos contemplar a atual estrutura dos sistemas de comunicação, a atual estrutura do ambiente das novas mídias, a estrutura de redes descentralizadas e geometria fractal.

No passado, usei a expressão tribalismo líquido para tentar expressar essa nova forma de tribalismo que McLuhan nos apontou (Strate,
1996). Outros o chamaram de glocalização. McLuhan chamou-o de aldeia global. Mas, afinal, essas expressões são como experimentos do pensamento, como a história apócrifa de Galileu deixando cair uma bala de canhão e uma bola de lã do alto da torre de Pisa. São sondas que pedem que pensemos sobre nossas noções de gravidade, que estão mudando, e sobre nosso centro de gravidade, também em mutação. Assim como nossas constelações passaram da Galáxia de Gutenberg para a Via Láctea de Marconi, estamos situados dentro de um novo tipo de Zodíaco, tentando desesperadamente traçar horóscopos que expliquem as forças que nos afetam. Mas, para entender nosso novo ambiente humano e conquistar algum grau, por reduzido que seja, de controle sobre ele, precisamos de um novo tipo de educação ajustado ao nosso universo midiacêntrico, precisamos de uma educação baseada em um currículo de ecologia da mídia e da moderna ciência da mídia de Marshall McLuhan.

\section{Referências}

Anderson, B. (1983). Imagined communities: Reflections on the origin and spread of nationalism. London: Verso.

Benjamin, W. (1968). Illuminations (H. Zohn, Trans.). New York: Harcourt, Brace \& World.

Braudy, L. (1986). The frenzy of renown: Fame and its history. New York: Oxford University Press.

Carey, J. W. (1989). Communication as culture: Essays on media and society. Boston: Unwin Hyman.

Carey, J. W. (1997). James Carey: A critical reader (E. S. Munson \& C. A. Warren, Eds.). Minneapolis: University of Minnesota Press. 
Carpenter, E. (1973). Oh, what a blow that phantom gave me! New York: Holt, Rinehart \& Winston.

Chaytor, H.J. (1945). From script to print. Cambridge: Cambridge University Press.

Coward, B. (1980). The Stuart age. London: Longman.

Czitrom, D. J. (1983). Media and the American mind : From Morse to McLuhan. University of North Carolina Press.

Deibert, R. J. (1997). Parchment, printing, and hypermedia: Communication in world order transformation. New York: Columbia University Press.

Deutsch, K.W. (1953). Nationalism and social communication: An inquiry into the foundations of nationalism. Cambridge, MA: MIT Press.

Drucker, P.F. (1989). The new realities. New York: Harper \& Row.

Eisenstein, E. L. (1979). The printing press as an agent of change: Communications and cultural transformations in early modern Europe. 2 vols. New York: Cambridge University Press.

Ellul, J. (1964). The technological society (J.

Wilkinson, Trans.). New York: Knopf.

Ellul, J. (1965). Propaganda: The formation of men's attitudes (K. Kellen \& J. Lerner, Trans.). New York: Vintage.

Fuller, R. B. (1971). Operating manual for spaceship earth. New York: E.P. Dutton.

Goody, J. (1986). The logic of writing and the organization of society. Cambridge: Cambridge University Press.

Gramsci, A. (1972). Selections from the Prison Notebooks of Antonio Gramsci (Q. Hoare \& G.N. Smith, Eds. \& Trans.). New York: International. Habermas, J. (1989). The structural transformation of the public sphere: An inquiry into a category of bourgeois society (T. Burger, Trans.). Cambridge, MA: MIT Press.

Hall, E. T. (1959). The silent language. Garden City: Doubleday.

Havelock, E.A. (1963). Preface to Plato. Cambridge, MA: The Belknap Press of Harvard University Press.

Innis, H. A. (1951). The bias of communication.

Toronto: University of Toronto Press.

Knelman, F. (1978). Anti-nation: Transition to sustainability. Oakville, ON: Mosaic Press.

Langer, S. K. K. (1957). Philosophy in a new key: A study in the symbolism of reason, rite and art (3rd ed.). Cambridge, MA: Harvard University Press.

Lee, D. (1959). Freedom and culture. Englewood Cliffs, NJ: Prentice-Hall.

Luhmann, N. (1982). The differentiation of society

(S. Holmes \& C. Larmore, Trans.). New York: Columbia University Press.

Luhmann, N. (1989). Ecological communication (J. Bednarz, Jr., Trans.). Chicago: University of Chicago Press.

Luhmann, N. (1995). Social systems (J. Bednarz , Jr. with D. Baecker, Trans.). Stanford: Stanford University Press.

Marx, K. \& Engels, F. (1965). The Communist manifesto (S. Moore, Trans.). New York: Washington Square Press.

McLuhan, M. (1962). The Gutenberg galaxy: The making of typographic man. Toronto: University of Toronto Press.

McLuhan, M. (1964). Understanding media: The extensions of man. New York: McGraw-Hill.

McLuhan, M. \& Fiore, Q. (1967). The medium is the massage: An inventory of effects. New York: Bantam. McLuhan, M. \& McLuhan, E. (2011). Media and 
formal cause. Houston: NeoPoiesis Press.

McLuhan, M. \& Powers, B. R. (1989). The global village: Transformations in world life and media in the twentyfirst century. New York: Oxford University Press.

Meyrowitz, J. (1985). No sense of place: The impact of electronic media on social behavior. New York: Oxford University Press.

Mumford, L. (1934). Technics and civilization. New York: Harcourt Brace.

Mumford, L. (1967). The myth of the machine: I. Technics and human development. New York: Harcourt Brace and World.

Mumford, L. (1970). The myth of the machine: II The pentagon of power. New York: Harcourt Brace Jovanovich.

Nagy, G. (1979). The best of the Achaeans. Baltimore: John Hopkins University Press.

Ong, W.J. (1967). The presence of the word: Some prolegomena for cultural and religious history. Minneapolis, MN: University of Minnesota Press.

Ong, W. J. (1982). Orality and literacy: The technologizing of the word. London: Routledge.

Postman, N. (1970). The reformed English curriculum. In A.C. Eurich (Ed.), High school 1980: The shape of the future in American secondary education (pp.160168). New York: Pitman.

Postman, N. (1985). Amusing ourselves to death: Public discourse in the age of show business. New York: Viking.

Postman, N. (1988). Conscientious objections: Stirring up trouble about language, technology, and education. New York: Alfred A. Knopf.

Postman, N. (1992). Technopoly: The surrender of culture to technology. New York: Alfred A. Knopf. Rushkoff, D. (2009). Life Inc.: How the world became a corporation and how to take it back. New York: Random House.

Sontag, S. (1977). On photography. New York: Farrar, Straus \& Giroux.

Steinberg, S. H. (1974). Five hundred years of printing (3rd ed.). New York: Penguin.

Strate, L. (1996). Cybertime. In L. Strate, R.L. Jacobson, \& S. Gibson (Eds.), Communication and cyberspace: Social interaction in an electronic environment (pp. 351-377). Cresskill, NJ: Hampton Press. (pp. 361-387 in 2nd ed., 2003).

Strate, L. (2006). Echoes and reflections: On media ecology as a field of study. Cresskill, NJ: Hampton Press.

Strate, L. (2011). On the binding biases of time and other essays on general semantics and media ecology. Fort Worth, TX: Institute of General Semantics.

Strate, L. \& Wachtel, E. A. (2005). The legacy of McLuhan. Cresskill, NJ: Hampton Press.

Whorf, B. L. (1956). Language, thought, and reality. Cambridge, MA: MIT Press. 


\section{The Fate of Social} Systems in the New Media Environment

\section{Abstract}

Marshall McLuhan put forth a mediacentric view of the world, expressed in his famous maxim, the medium is the message. This view, and McLuhan's work as a scholar, were deliberately suppressed for many years, until the internet became a popular phenomenon during the 1990s. McLuhan's observations about electricity, electric technology, and electronic media, resulting in a change in media environment from the Gutenberg galaxy to the Marconi Milky Way are essential for understanding the new media that have appeared over the past two decades. Specifically examining the relationship between media and social organization, the rise of nationalism and the nation-state is traced back to the printing revolution in early modern Europe, while contemporary trends towards globalism on the one hand, and new forms of localism and tribalism on the other, are associated with electronic communications and the new media.

\section{Key Terms}

McLuhan, media, media ecology, media environment, print media, electronic media, new media, nationalism, globalism.

\section{La caída de las naciones: el destino de los sistemas sociales en el nuevo entorno mediático}

\section{Resumen}

Marshall McLuhan planteó una visión mediacentrica del mundo, expresa en su famosa máxima, el medio es el mensaje. Este punto de vista, y la obra de McLuhan como académico, se suprimieron deliberadamente durante muchos años, hasta que el Internet se convirtió en un fenómeno popular durante la década de 1990. Las observaciones de McLuhan acerca de la electricidad, la tecnología eléctrica y los medios electrónicos, dando como resultado un cambio en el entorno de los medios de comunicación de la galaxia de Gutenberg a la Vía Láctea de Marconi son esenciales para la comprensión de los nuevos medios que han surgido en las dos últimas décadas. Específicamente examino la relación entre los medios de comunicación y la organización social: el auge del nacionalismo y el Estado-nación se remonta a la revolución de la imprenta en la Europa moderna, mientras que las tendencias actuales a la globalización por un lado, y las nuevas formas de localismo y el tribalismo por el otro, están asociados a las comunicaciones electrónicas y los nuevos medios.

\section{Palabras clave}

McLuhan, medios, ecología mediática, medios impresos, medios electrónicos, nuevos medios, nacionalismo, globalización. 


\section{Expediente}

A revista E-Compós é a publicação científica em formato eletrônico da Associação Nacional dos Programas de Pós-Graduação em Comunicação (Compós). Lançada em 2004, tem como principal finalidade difundir a produção acadêmica de pesquisadores da área de Comunicação, inseridos em instituições do Brasil e do exterior.
E-COMPÓS I www.e-compos.org.br I E-ISSN 1808-2599

Revista da Associação Nacional dos Programas

de Pós-Graduação em Comunicação.

Brasília, v.14, n.3, set./dez. 2011.

A identificação das edições, a partir de 2008

passa a ser volume anual com três números.

\section{CONSELHO EDITORIAL}

Afonso Albuquerque, Universidade Federal Fluminense, Brasil Alberto Carlos Augusto Klein, Universidade Estadual de Londrina, Brasi Alex Fernando Teixeira Primo, Universidade Federal do Rio Grande do Sul, Brasil Ana Carolina Damboriarena Escosteguy, Pontifícia Universidade Católica do Rio Grande do Sul, Brasil

Ana Gruszynski, Universidade Federal do Rio Grande do Sul, Brasil Ana Silvia Lopes Davi Médola, Universidade Estadual Paulista, Brasil André Luiz Martins Lemos, Universidade Federal da Bahia, Brasil Ângela Freire Prysthon, Universidade Federal de Pernambuco, Brasil Angela Cristina Salgueiro Marques, Faculdade Cásper Líbero (São Paulo), Brasil Antônio Fausto Neto, Universidade do Vale do Rio dos Sinos, Brasil Antonio Carlos Hohlfeldt, Pontifícia Universidade Católica do Rio Grande do Sul, Brasil Antonio Roberto Chiachiri Filho, Faculdade Cásper Líbero, Brasil Arlindo Ribeiro Machado, Universidade de São Paulo, Brasil

Arthur Autran Franco de Sá Neto, Universidade Federal de São Carlos, Brasil Benjamim Picado, Universidade Federal Fluminense, Brasil César Geraldo Guimarães, Universidade Federal de Minas Gerais, Brasi Cristiane Freitas Gutfreind, Pontifícia Universidade Católica do Rio Grande do Sul, Brasi Denilson Lopes, Universidade Federal do Rio de Janeiro, Brasil Denize Correa Araujo, Universidade Tuiuti do Paraná, Brasil

Edilson Cazeloto, Universidade Paulista , Brasi

Eduardo Peñuela Cañizal, Universidade Paulista, Brasi Eduardo Vicente, Universidade de São Paulo, Brasi Eneus Trindade, Universidade de São Paulo, Brasil Erick Felinto de Oliveira, Universidade do Estado do Rio de Janeiro, Brasil Florence Dravet, Universidade Católica de Brasilia, Brasil Francisco Eduardo Menezes Martins, Universidade Tuiuti do Paraná, Brasil Gelson Santana, Universidade Anhembi/Morumbi, Brasil Gilson Vieira Monteiro, Universidade Federal do Amazonas, Brasil Gislene da Silva, Universidade Federal de Santa Catarina, Brasil Guillermo Orozco Gómez, Universidad de Guadalajara Gustavo Daudt Fischer, Universidade do Vale do Rio dos Sinos, Brasil Hector Ospina, Universidad de Manizales, Colômbia Herom Vargas, Universidade Municipal de São Caetano do Sul, Brasil leda Tucherman, Universidade Federal do Rio de Janeiro, Brasi Inês Vitorino, Universidade Federal do Ceará, Brasil Janice Caiafa, Universidade Federal do Rio de Janeiro, Brasi Jay David Bolter, Georgia Institute of Technology Jeder Silveira Janotti Junior, Universidade Federal de Pernambuco, Brasil João Freire Filho, Universidade Federal do Rio de Janeiro, Brasi John DH Downing, University of Texas at Austin, Estados Unido José Afonso da Silva Junior, Universidade Federal de Pernambuco, Brasil
José Carlos Rodrigues, Pontifícia Universidade Católica do Rio de Janeiro, Brasil José Luiz Aidar Prado, Pontifícia Universidade Católica de São Paulo, Brasil José Luiz Warren Jardim Gomes Braga, Universidade do Vale do Rio dos Sinos, Brasi Juremir Machado da Silva, Pontifícia Universidade Católica do Rio Grande do Sul, Brasil Laan Mendes Barros, Universidade Metodista de São Paulo, Brasil Lance Strate, Fordham University, USA, Estados Unidos Lorraine Leu, University of Bristol, Grã-Bretanha Lucia Leão, Pontifícia Universidade Católica de São Paulo, Brasil Luciana Panke, Universidade Federal do Paraná, Brasil Luiz Claudio Martino, Universidade de Brasília, Brasil Malena Segura Contrera, Universidade Paulista, Brasi Márcio de Vasconcellos Serelle, Pontifícia Universidade Católica de Minas Gerais, Brasil Maria Aparecida Baccega, Universidade de São Paulo e Escola Superior de Propaganda e Marketing, Brasil

Maria das Graças Pinto Coelho, Universidade Federal do Rio Grande do Norte, Brasil Maria Immacolata Vassallo de Lopes, Universidade de São Paulo, Brasil Maria Luiza Martins de Mendonça, Universidade Federal de Goiás, Brasil Mauro de Souza Ventura, Universidade Estadual Paulista, Brasil Mauro Pereira Porto, Tulane University, Estados Unidos Nilda Aparecida Jacks, Universidade Federal do Rio Grande do Sul, Brasil Paulo Roberto Gibaldi Vaz, Universidade Federal do Rio de Janeiro, Brasi Potiguara Mendes Silveira Jr, Universidade Federal de Juiz de Fora, Brasil Renato Cordeiro Gomes, Pontifícia Universidade Católica do Rio de Janeiro, Brasil Robert K Logan, University of Toronto, Canadá

Ronaldo George Helal, Universidade do Estado do Rio de Janeiro, Brasil Rosana de Lima Soares, Universidade de São Paulo, Brasil Rose Melo Rocha, Escola Superior de Propaganda e Marketing, Brasil Rossana Reguillo, Instituto de Estudos Superiores do Ocidente, Mexico Rousiley Celi Moreira Maia, Universidade Federal de Minas Gerais, Brasil Sebastião Carlos de Morais Squirra, Universidade Metodista de São Paulo, Brasil Sebastião Guilherme Albano da Costa, Universidade Federal do Rio Grande do Norte, Brasil

Simone Maria Andrade Pereira de Sá, Universidade Federal Fluminense, Brasi Tiago Quiroga Fausto Neto, Universidade de Brasília, Brasil Suzete Venturelli, Universidade de Brasília, Brasil Valério Cruz Brittos, Universidade do Vale do Rio dos Sinos, Brasil Valerio Fuenzalida Fernández, Puc-Chile, Chile

Veneza Mayora Ronsini, Universidade Federal de Santa Maria, Brasil Vera Regina Veiga França, Universidade Federal de Minas Gerais, Brasil Valerio Fuenzalida Fernández, Puc-Chile, Chile Veneza Mayora Ronsini, Universidade Federal de Santa Maria, Brasil Vera Regina Veiga França, Universidade Federal de Minas Gerais, Brasil

\section{COMISSÃO EDITORIAL}

Adriana Braga I Pontifícia Universidade Católica do Rio de Janeiro, Brasil Felipe Costa Trotta I Universidade Federal de Pernambuco, Brasi

CONSULTORES AD HOC

Édison Gastaldo, Universidade Federal Rural do Rio de Janeiro, Brasil

EDIÇÃO DE TEXTO E RESUMOS I Susane Barros

SECRETÁRIA EXECUTIVA I Juliana Depiné

EDITORAÇÃo ELETRÔNICA I Roka Estúdio

TRADUÇÃo I Sieni Campos e Robert Finnegan
COMPós I www.compos.org.br

Associação Nacional dos Programas de Pós-Graduação em Comunicação

Presidente

Julio Pinto

Pontifícia Universidade Católica de Minas Gerais, Brasi

juliopinto@pucminas.br

Vice-presidente

Itania Maria Mota Gomes

Universidade Federal da Bahia, Brasi

itania@ufba.br

Secretária-Geral

Inês Vitorino

Universidade Federal do Ceará, Brasil

inesvict@gmail.com 